\title{
Educação de jovens e adultos: modalidade de ensino e direito educacional
}

\author{
Youth and adult education: type of education and educational law \\ Educación de jóvenes y adultos: modalidadde enseñanza y derecho educativo \\ VALDIVINA ALVES FERREIRA \\ MARCILENE FERREIRA RODRIGUES
}

Resumo: Este artigo tem por finalidade apresentar uma reflexão acerca da Educação de Jovens e Adultos (EJA), enquanto modalidade de ensino e direito educacional. As análises advêm de um estudo documental e bibliográfico, dialogado com autores que debatem a temática, entre eles Ferreira (2004), Vieira (2001), Frigotto (2011), Cury (2014). A reflexão se dá a partir da Constituição Federal de 1988, levantando subsídios que identifiquem como foi introduzido o conceito de modalidade de ensino e, ainda, como essa proposta dialoga com o direito à educação de qualidade, uma vez que a educação é apreendida por um arcabouço legal que visa à garantia do direito subjetivo a ela conferido. Todavia os resultados parciais deste estudo sinalizam que as propostas neoliberais visam a um processo de ampliação e manutenção do sistema vigente; esse percurso influencia a minimização do direito à educação de qualidade dos sujeitos da Educação de Jovens e Adultos.

Palavras-chave: Educação de Jovens e Adultos; Modalidade de Ensino; Direito Educacional.

\begin{abstract}
This article aims to present a reflection on the Youth and Adult Education, as a type of teaching and educational law. The analysis comes from a documentary and bibliographical research, dialogues with authors who debate on the subject including Ferreira (2004), Vieira (2001), Frigotto (2011) Cury (2014), among others. The reflection takes place from the 1988 Federal Constitution, raising subsidies to identify how it was introduced to the concept of teaching mode and how this proposal converses with the right to a quality education, since a legal framework seizes education and aims to guarantee the subjective right granted to it. However, the partial results of the study indicate that neoliberal proposals aim a process of expansion and maintenance of the current system, and in this way influence the minimization of the right to quality education to the subjects of the Youth and Adult Education.
\end{abstract}

Keywords: Youth and Adult Education; type of education; educational law.

Resumen: Este artículo tiene como objetivo presentar una reflexión sobre laeducación de jóvenes y adultos (EJA), como unamodalidad de enseñanza y derecho educativo. Los análisisprovienen de unestudio documental y bibliográfico, dialogado con autores que debaten sobre el tema, incluyendo Ferreira (2004), Vieira (2001), Frigotto (2011) Cury (2014), entre otros. La reflexión se lleva a cabo a partir de laConstitución Federal de 1988, elevando 
lossubsidios que identifiquencómofueintroducidoel concepto de modalidad de enseñanza y tambiéncómo esta propuesta dialoga conelderecho a laeducación de calidad, ya que laeducación es aprehendida por un marco legal que tiene como objetivo garantizarelderecho subjetivo que lefue concedida. Sin embargo, los resultados parcialesdelestudio, indican que laspropuestasneoliberalestienen como objetivo unproceso de expansión y mantenimientodel sistema actual, y de esta manerainfluyenenlareducción al mínimo delderecho a laeducación de calidad a lossujetosde la Educación de Jóvenes y Adultos.

Palabras clave: Educación de jóvenes y adultos; modalidad de enseñanza; Derecho Educativo.

\section{INTRODUÇÃO}

O texto que aqui se apresenta é parte de uma pesquisa de mestrado em andamento, vinculada ao Grupo de Pesquisa Políticas de Formação e Trabalho Docente na Educação Básica, do Programa de Pós-Graduação em Educação Mestrado e Doutorado - da Universidade Católica Dom Bosco (UCDB). Temse a intenção, na pesquisa, de analisar o processo de implementação do Exame Nacional para Certificação de Competências de Jovens e Adultos no Estado de Mato Grosso do Sul, no período de 2010 a 2015. Neste artigo, porém, propõe-se realizar uma reflexão acerca da Educação de Jovens e Adultos (EJA), evidenciando essa modalidade de ensino enquanto direito educacional.

As ponderações advêm de um estudo documental e bibliográfico, dialogado com autores que debatem a temática, entre eles Ferreira (2004), Frigotto (2011), Vieira (2001), Cury (2014), Sader (2004) e Saviani (2007). Cotejam-se também os preceitos da Constituição Federal de 1988 e da Lei de Diretrizes e Bases da Educação Nacional de 1996, no intuito de se levantarem subsídios que identifiquem como foi introduzida essa modalidade de ensino no cenário das políticas públicas educacionais, buscando-se identificar como a EJA está apreendida pelo arcabouço de propostas que, nos discursos neoliberais, sinalizam sua intenção no que diz respeito à garantia do direito subjetivo a ela conferido, processo de acesso, permanência e qualidade, defendido por Saviani (2007).

Dessa maneira, as análises buscaram identificar também os entrelaces da Educação de Jovens e Adultos e as intenções neoliberais ${ }^{1}$, que focalizam e minimizam os efeitos das propostas para essa modalidade de ensino, uma vez que esta se encontra associada diretamente às Políticas Públicas, as quais se

$1 \quad$ Nesse sentido, afirma Sader (2004) que, "as políticas neoliberais, ao orientarem-se centralmente pela retração do Estado, abrem espaços para a extensão das relações mercantis, se chocam diretamente com os interesses públicos e com os direitos universais da grande maioria dos cidadãos”(p.9). 
apresentam de forma antagônica, evidenciando um mascaramento dos diferentes entendimentos e as disputas ideológicas e hegemônicas que as cerceiam.

Os resultados parciais sinalizam que, no contexto atual das políticas públicas, as propostas neoliberais visam a um processo de ampliação e permanência do sistema vigente. Dessa forma, entende-se ser necessário fomentar a Educação de Jovens e Adultos enquanto modalidade de ensino e enquanto direito assegurado, buscando a garantia de uma educação de qualidade, e que essa educação seja capaz de contribuir para a formação de cidadãos ativos e participativos na sociedade em que vivem.

\section{EDUCAÇÃO DE JOVENS E ADULTOS, ENQUANTO MODALIDADE DE ENSINO}

A discussão acerca da Educação de Jovens e Adultos vem assumindo características e formas cada vez mais acentuadas na atualidade; essas manifestações advêm de vários elementos, entre os quais a certificação de competência, acesso, permanência, aceleração do ensino. Essas são questões norteadoras dessa modalidade de ensino, que abrange uma parcela da população que não desfruta de condições que lhes garanta o direito a uma educação continuada e de qualidade, com capacidade de gerar cidadãos críticos e participativos.

Contudo o direito à educação de qualidade deveria atribuir ao sujeito um papel que the conferisse liberdade de decisão sobre sua condição cidadã ou, ainda, seu futuro enquanto sujeito de uma nação; este não parece ser, porém, o interesse neoliberal, que reveste as políticas públicas com um papel mercadológico e focalizado, criando ainda uma falsa ideia de participação da sociedade civil, formatando a educação de jovens e adultos de modo a atender às manobras capitalistas e a seus vieses na sociedade desigual criada pelo capitalismo.

No contexto de redemocratização do país, com várias reorganizações internas foi promulgada a Constituição Federal de 1988 (BRASIL, 1988). A Carta Magna assegura o direito universal à educação, com Ensino Fundamental público e gratuito, independente de idade, conforme explicitado no art. 208, ao prescrever o "dever do Estado com a educação, mediante a garantia de ensino fundamental, obrigatório e gratuito, inclusive para os que a ele não tiveram acesso na idade própria”.

Por certo que o direito à educação de qualidade a todos os cidadãos é expresso também no art. 205, que estabelece ser a "a educação direito de todos e dever do Estado [...], visando ao pleno desenvolvimento da pessoa, seu preparo para o exercício da cidadania e sua qualificação para o trabalho". Esse direito se configura, então, enquanto elemento fundamental para a cidadania, constituindo- 
se numa sociedade de direito, mais democrática e igualitária tal como descrito na Constituição (BRASIL, 1988).

O texto legal a que se refere acima se constitui um marco para a política educacional, a qual assume papel mediador na sociedade brasileira, capaz de, ou com a atribuição de fazê-lo, resgatar milhares de brasileiros ainda na condição de analfabetos e marginalizados.

Nesse contexto de aquisições regulamentatórias, promulgada em 1996, a Lei de Diretrizes e Bases da Educação Nacional (LDB) organiza o sistema educacional brasileiro em dois níveis de ensino: a Educação Básica - formada pela Educação Infantil, Ensino Fundamental e Ensino Médio - e o Ensino Superior. A Educação Básica pode ser ofertada nas seguintes modalidades: educação de jovens e de adultos, educação profissional, educação especial, educação indígena e educação a distância. Assim explicita a LDB em seu art. 37:

\footnotetext{
Art. 37. A educação de jovens e adultos será destinada àqueles que não tiveram acesso ou continuidade de estudos no ensino fundamental e médio na idade própria. [...] $\int 1^{\circ}$ Os sistemas de ensino assegurarão gratuitamente aos jovens e aos adultos, que não puderam efetuar os estudos na idade regular, oportunidades educacionais apropriadas, consideradas as características do alunado, seus interesses, condições de vida e de trabalho, mediante cursos e exames (BRASIL, 1996).
}

Assim, a Educação de Jovens e Adultos, tratada na Lei como modalidade integrante da Educação Básica, destina-se ao atendimento de alunos que não tiveram, na idade própria, acesso ou continuidade de estudo no Ensino Fundamental e Médio, explicitando que compete aos sistemas de ensino assegurar gratuitamente oportunidades educacionais, de maneira adequada, àqueles que não concluíram seus estudos em idade apropriada, por meio dos cursos e exames supletivos (Idem).

Observa-se que o texto da Lei mantém o adjetivo supletivo para tratar dos exames, assim descritos no art. 38: "os sistemas de ensino manterão cursos e exames supletivos, que compreenderão a base nacional comum do currículo, habilitando ao prosseguimento de estudos em caráter regular" (Idem).

Denota, dessa maneira, uma incoerência, pois, se a LDB instaura a Educação de Jovens e Adultos no sentido de promover, assegurar e manter o desenvolvimento do ensino com qualidade a esses sujeitos, o termo supletivo reporta a um paralelismo, ou seja, flexibiliza essa modalidade, criando lacunas para a aceleração dos estudos, admitindo o acesso a avaliações de conhecimento adquiridos de maneira informal, desresponsabilizando o Estado de garantir oferta de um ensino universal e de qualidade, uma vez que este o faz mediante propostas reducionistas e pontuais (FRIEDRICH et al.,2010). 
Isso configura ainda uma precarização do ensino, com a redução das idades para a prestação desses exames supletivos, conforme exposto no art. 38 da Lei de Diretrizes e Bases da Educação Nacional,

$\int 1^{\circ}$ Os exames a que se refere este artigo realizar-se-ão: I - no nível de conclusão do ensino fundamental, para os maiores de quinze anos; II - no nível de conclusão do ensino médio, para os maiores de dezoito anos. $\$ 2^{\circ}$ Os conhecimentos e habilidades adquiridos pelos educandos por meios informais serão aferidos e reconhecidos mediante exames (BRASIL, 1996).

A LDB de 1996 apresenta como fator novo e significativo apontamento para a EJA o rebaixamento da idade mínima para os exames supletivos de 18 para 15 e de 21 para 18, nas etapas de Ensino Fundamental e Médio respectivamente, como tentativa de correção do fluxo do sistema escolar, ou seja, institui-se a idade mínima e permite-se a aceleração do ensino, abandonando-se a representatividade dessa deliberação na educação de jovens e adultos.

É importante ressaltar que o Parecer CNE/CEB no 11/2000, fundamentado pela Lei 9394/96, traz três funções básicas do ensino de caráter regular à Educação de Jovens e Adultos:

função reparadora da EJA, no limite, significa não só a entrada no circuito dos direitos civis pela restauração de um direito negado: o direito a uma escola de qualidade, mas também o reconhecimento daquela igualdade ontológica de todo e qualquer ser humano. Desta negação, evidente na história brasileira, resulta uma perda: o acesso a um bem real, social e simbolicamente importante. Logo, não se deve confundir a noção de reparação com a de suprimento. [...] A função equalizadora da EJA vai dar cobertura a trabalhadores e a tantos outros segmentos sociais como donas de casa, migrantes, aposentados e encarcerados. A reentrada no sistema educacional dos que tiveram uma interrupção forçada seja pela repetência ou pela evasão, seja pelas desiguais oportunidades de permanência ou outras condições adversas, deve ser saudada como uma reparação corretiva, ainda que tardia, de estruturas arcaicas, possibilitando aos indivíduos novas inserções no mundo do trabalho, na vida social, nos espaços da estética e na abertura dos canais de participação. Para tanto, são necessárias mais vagas para estes "novos" alunos e "novas" alunas, demandantes de uma nova oportunidade de equalização. [...] função permanente da EJA que pode se chamar de qualificadora. Mais do que uma função, ela é o próprio sentido da EJA. Ela tem como base o caráter incompleto do ser humano cujo potencial de desenvolvimento e de adequação pode se atualizar em quadros escolares ou não escolares. Mais do que nunca, ela é um apelo para a educação permanente e criação de uma sociedade educada para o universalismo, a solidariedade, a igualdade e a diversidade (BRASIL, 1996).

Essas funções reportam ao caráter ampliado da Educação de Jovens e Adultos, enquanto modalidade de educação, a qual assume o papel de formação educacional e humana, na busca de propiciar ao sujeito condições para ter um 
comportamento ético e político, através do desenvolvimento da autonomia e da reflexão crítica sobre a realidade em que se situa.

Contudo é necessário ter em vista as especificidades de seus educandos, seus interesses, condições de vida e de trabalho, com os contextos de negação ao ensino desde o processo de colonização do país e que vêm ganhando proporção ao longo do tempo. Esse item necessita ser repensado no que toca a sua realização através da suplementação de ensino ou de seu aligeiramento, com certificação ${ }^{2}$, utilizados, muitas vezes, para atingir índices de redução de analfabetismo.

A concepção de avaliar para certificar se relaciona diretamente à ideia de elevação do nível de escolaridade, sendo explicitada, na visão de Bertrand (2005), como:

\begin{abstract}
A operação que garante as competências e as habilidades (savoir-faire) de um indivíduo em relação a uma norma formalizada. $O$ valor da certificação para os indivíduos baseia-se também na possibilidade de acesso a um nível educacional superior, a um emprego ou, inclusive, a certo prestígio social. Pode também ser um elemento de definição da identidade dos indivíduos e das profissões. Pode constituir uma linha divisória entre os que possuem um título e os que têm necessidade dele [...] a certificação pode ser um instrumento de referência que permite medir os progressos e avaliar os resultados que não só interessam ao sistema de formação, como também ao desenvolvimento socioeconômico, em seu conjunto (pp. 13 e 15).
\end{abstract}

Ao longo da história da educação brasileira, tem-se verificado alto índice de analfabetismo, a alfabetização tardia, a evasão escolar, a falta de acesso à educação para todos os brasileiros, a ausência de condições dignas de trabalho e remuneração aos professores. Trata-se de categorias que devem ser repensadas em sua relação com a diversidade, de modo a se efetivar a garantia do processo de ensino e aprendizagem a todos os cidadãos de direitos. O que se observa é que a certificação do ensino, sem efetivamente viabilizar as condições para garantir a permanência desse sujeito, no âmbito educacional ou profissional, considerando a competitividade de ambos os setores, pode não lhe garantir a devida qualidade.

2

A certificação é o processo negociado pelas representações dos setores sociais e regulado pelo Estado, pelo qual se identificam, avaliam e validam formalmente os conhecimentos, saberes, competências, habilidades e aptidões profissionais desenvolvidos em programas educacionais ou na experiência de trabalho, com o objetivo de promover o acesso, a permanência e a progressão no mundo do trabalho e o prosseguimento ou conclusão de estudos (BRASIL, 2005). 


\section{O DIREITO À EDUCAÇÃO E A EDUCAÇÃO DE JOVENS E ADULTOS}

A educação brasileira, em vários momentos da história, é posta como elemento mediador entre a sociedade, o direito à educação de qualidade e a primazia dos interesses do Estado, sustentada pela imprescindível legitimidade dos governos, que sempre buscam as condições sociais necessárias para manterse no poder e, seletivamente, aparentam aceitar as reivindicações da sociedade e atender a sua demanda, mas estabelecem certa complacência no que diz respeito ao direito à educação.

Porém, no caso da EJA, essa tendência usual dos governantes de demonstrar intenção de agradar às classes populares não é tão transparente e, muito menos, resoluta, uma vez que o contingente de brasileiros analfabetos é alto e soma-se ao dos evadidos das salas de aulas, às distorções idade-série, fatores que se apresentam como barreiras no sistema educacional e para as políticas educacionais por meio das quais o Estado parece, em determinados momentos, ser o fiador da solução dessas questões.

A Constituição Federal de 1988 consagra, por sua vez, um estado de direito democrático e explicita o regime jurídico para a educação, requerendo a prestação de serviços educacionais com qualidade para todos os brasileiros; seu artigo 214 assim estabelece:

O plano nacional de educação, de duração decenal, com o objetivo de articular o sistema nacional de educação em regime de colaboração e definir diretrizes, objetivos, metas e estratégias de implementação para assegurar a manutenção e desenvolvimento do ensino em seus diversos níveis, etapas e modalidades por meio de ações integradas dos poderes públicos das diferentes esferas federativas que conduzam a: [...] I - erradicação do analfabetismo; [...] II - universalização do atendimento escolar; [...] III - melhoria da qualidade do ensino; [...] IV - formação para o trabalho; [...] V- promoção humanística, científica e tecnológica do País. [...] VI- estabelecimento de meta de aplicação de recursos públicos em educação como proporção do produto interno bruto (BRASIL, 1988).

Esse processo traz para a modalidade de ensino EJA um arcabouço de propostas que visam à garantia do direito subjetivo a ela conferido, para que ela seja concedida a todos os cidadãos num processo em que lhes sejam permitidos o acesso a um ensino de qualidade e a permanência nele, conceitos que deveriam sobrepor-se ao caráter fragmentário, pontual e emergencial ao qual essa modalidade de ensino vem sendo exposta, condição que demonstra o relativismo com que as políticas públicas têm tratado a demanda da população diante dos interesses da sociedade neoliberal, cujo centro de interesse é o mercado. 
Segundo Cury (2014),

\begin{abstract}
Qualidade também pode ser apontada como capacidade para efetuar uma ação ou atingir uma certa finalidade. O termo qualidade advém do latim qualitas, mas cuja procedência mais funda é a de poiótês do grego e que significa um título definidor de uma categoriza $\neg$ ção ou classificação. De certo modo, estamos no campo de um atributo distintivo de um bem que passa a se apresentar com uma característica particular além da comum. Por vezes, essa distinção costuma ser assinalada com uma adjetivação como no caso de qualidade social, qualidade total, entre outras. A qualidade, até por essa origem greco-latina, é um termo polissêmico e cuja definição não só carece de uniformidade como também se louva em sentidos de muita complexidade (p. 1054).
\end{abstract}

Geralmente, o direito à educação de qualidade entra em choque com o neoliberalismo, considerando-se que "as políticas neoliberais negam os direitos sociais", tornam-se balizas de um Estado mínimo que afaga, tripudia e "garante o mínimo de sobrevivência aos indigentes, que exige contrapartida para o gozo dos benefícios, que vincula diretamente o nível de vida ao mercado, transformando-o em mercadoria" (VIEIRA, 2001, p.11).

Todavia buscar o equilíbrio entre os pontos íngremes das políticas neoliberais e o direito à educação consiste em evidenciar os interesses que mantêm as manobras desse caminho que conduz a educação brasileira, principalmente na modalidade de ensino para jovens e adultos, ao ranqueamento das dívidas sociais do Estado brasileiro para com a sociedade, que, por certo, não garante o direito igual a todos os cidadãos. Segundo Saviani (2007, p.1232), convivemos com uma realidade em que a Educação se apresenta como "dever de todos e direito do Estado". De acordo com o autor, essa estratégia vai da "cumplicidade entre o público e o privado, passa pelo favorecimento à privatização e chega à transferência do dever de educar para a sociedade civil, assegurando-se ao Estado o direito de controle".

Tal controle, ao ser utilizado como instrumento de manipulação, transfere para a educação o discurso inclusivo a todos os cidadãos, enaltecendo sua importância diante da complexidade da vida moderna, mas também imbuída de aparar as arestas que o sistema capitalista deixa ao implantar programas e políticas públicas focais e restritivas. Nesse sentido, é necessário que a sociedade tome posse do estado democrático de direito que está posto legalmente, mas que será vislumbrado quando todos estiverem empoderados cientificamente e criticamente imbuídos de argumentos para quebrar a dominação do discurso, pois a "democracia não constitui um estágio, ela constitui um processo, pelo qual a soberania popular vai controlando e aumentando os direitos [...] é um processo 
prolongado, implicando avanço muito grande dentro da sociedade", afirma Vieira (2001, p.14).

Considerando que uma sociedade fortemente amparada pela democracia, pelo estado democrático de direito, mais mobilizada politicamente, torna-se uma sociedade ativa nas decisões e proposições, visando ao interesse geral, passa-se a exigir um procedimento diferenciado do Estado no que concerne às condições iguais a todos os cidadãos a uma educação de qualidade, seja no processo de acesso a ela seja no processo de permanência nela.

Notam-se, porém, alguns empecilhos nesse processo democrático de direitos previsto na Constituição Federal de 1988, entre os quais o disciplinamento a que esse direito é submetido, conforme interesses neoliberais. Em alguns momentos, ele significa "direitos individuais e sociais e, de outro, obrigações do Estado", oportunizando uma abundância de deliberações que lhe impossibilitam desvencilhar-se das armadilhas capitalistas que se congregam nas veemências do Estado (VIEIRA, 2001, p.25).

Esses emaranhados de condições criados pelo Estado formam jovens e adultos na iminência de atender seus interesses, os quais se limitam ao discurso genérico da democracia como a efetivação de uma gestão participativa e emancipatória, uma formação para cidadania, na qual o sujeito possa participar, com responsabilidade das decisões deliberativas do país e ter condições de contribuir com a oferta de uma educação de qualidade.

As propostas neoliberais vão ao encontro da produção de trabalhadores capacitados para o desempenho com competência de suas atividades laborais, os certificados com cursos técnicos. Essa persuasão pode ser iniciada com a certificação de nível fundamental através do Exame Nacional para Certificação de Competências de Jovens e Adultos (ENCCEJA), de ensino médio por intermédio do Exame Nacional do Ensino Médio (ENEM). Estas são estratégias que visam a diminuir o quantitativo de cidadãos analfabetos, mas condicionados, indiretamente, à ideologia excludente do capitalismo, isso porque aceleram a desigualdade entre a população, pois apenas uma parcela constituirá, meritocraticamente, dirigentes, e outra parcela, executores.

Nesse sentido, faz-se necessário instituir uma educação que possa acompanhar as mudanças ocorridas na sociedade, principalmente no que tange à "formação humana integral que se alicerça na ética humana", formação "secundarizada pelos ditames da produtividade e da competitividade que o neoliberalismo impõe" (FERREIRA, 2004, p. 1232).

Esses movimentos neoliberais geram paradigmas que contrastam

Com a história de resistência ativa de seus aparelhos de hegemonia e de seus intelectuais contra as teses da educação pública, gratuita, universal, laica e unitária, 
revela, a um tempo, o caráter cínico do movimento e a disputa ativa pela hegemonia do pensamento educacional mercantil no seio das escolas públicas [...] Pode-se afirmar, assim, que a despeito de algumas intenções em contrário, a estratégia de fazer reformas conciliando e não confrontando os interesses da minoria prepotente com as necessidades da maioria desvalida acaba favorecendo essa minoria, mantendo o dualismo estrutural na educação, a inexistência de um sistema nacional de educação, uma desigualdade abismal de bases materiais e de formação, condições de trabalho e remuneração dos professores, redundando numa pífia qualidade de educação para a maioria da população (FRIGOTTO, 2011, pp. 245 e 256).

O texto de Frigotto (2011) demonstra a existência de barreiras excludentes, princípio que cria evidentemente um distanciamento do direito à educação de qualidade, e a sua efetivação para todos os cidadãos brasileiros. A desigualdade de bases materiais citada pelo autor e a estratégia de reformas permitem entender os arranjos neoliberais e suas expertises, formando um campo de batalha no cenário educacional brasileiro que clama pela equalização de oportunidades e um padrão de qualidade no ensino ofertado.

Um dos resultados a se questionar, o da combinação entre um "mundo mergulhado no neoliberalismo e o avanço do direito à educação, tem sido a frustração diante da constatação de que os esforços por colocar a EJA na agenda dos governos não resultaram em avanços significativos", justamente pelos interesses imbuídos da educação de qualidade, que ainda não é para todos (DI PIERRO; HADAD, 2015, p.197).

\section{CONSIDERAÇÕES FINAIS}

A escolarização de jovens e adultos pode ser considerada, em toda a sua trajetória, como uma proposta direcionada contra as tentativas do Estado de minimizar os problemas decorrentes das lacunas geradas na educação nessa modalidade de ensino. Tem ostentado diferentes faces em seu desenvolvimento histórico, no qual assumiu, inclusive, o papel de complementar estudos e de suplementar da escolarização, ou seja, não buscou uma efetivação do direito à educação de qualidade, conforme previsto na Constituição Federal de 1988, minimizando o procedimento pedagógico e emancipatório dos cidadãos.

Contudo o processo histórico da educação de jovens e adultos demonstra tentativas de se avançar na luta pelo direito à educação, não apenas quanto ao acesso, mas na definição do conhecimento dessa modalidade de ensino frente a demandas populacionais que emergem na busca pelo direito à educação, prescrito na legislação.

Todavia os caminhos são antagônicos, com manifesto contraditório, imbuído de processos que retrocedem e se multiplicam nas políticas públicas

580 - RBPAE - v. 32, n. 2, p. 571 - 583 mai./ago. 2016 
que indicam a fragmentação das propostas para essa modalidade de ensino, com o aprofundamento das desigualdades sociais, não efetivando uma educação equânime, como garante a legislação.

Um exemplo desse processo é o exame nacional para a certificação de competência, que expressa uma ideologia excludente, formando um exército de educandos certificados, destacados da linha dos analfabetos, mas sem condições de análise da conjuntura cultural, social e política do país, à mercê da sorte de se tornarem cidadãos conscientes e capazes de participar ativamente das decisões que definem sua vida e sua sobrevivência nessa sociedade constituída sobre as diferenças entre as classes sociais, um campo minado por propostas reducionistas de direitos e revestidas de interesses privados.

O grande desafio, por certo, é gerar um diálogo entre essas propostas tão antagônicas, considerando que, de um lado, está a certificação de competências e, do outro, uma educação de qualidade que garanta a emancipação do cidadão e sua participação consciente em todos os campos, seja o político, o social, o cultural e o econômico. A busca por uma compreensão das diferentes determinações que levaram à incidência dessas propostas antagônicas e nosso posicionamento nos espaços em que atuamos se faz necessária, haja vista que, de uma forma ou de outra, estamos inseridos nesse processo, como já alertavam pesquisadores ao falarem sobre o percurso histórico controvertido da política de educação profissional no governo Lula (CIAVATTA; FRIGOTTO; RAMOS, 2005).

Entende-se que as expectativas convergem na direção da fomentação de uma educação de qualidade, com aplicabilidade de suas funções básicas, reparadora, equalizadora e permanente, conforme parecer CNE/CEB n ${ }^{\circ}$ 11/2000, fundamentado pela Lei 9394/96, que pondera sobre essas funções básicas do ensino de caráter regular, a Educação de Jovens e Adultos.

E, na iminência e perspectiva de levantar questionamentos a fim de propiciar novos estudos e, sugestivamente, iniciar novas análises sobre a Educação de Jovens e Adultos, considera-se a seguinte indagação: como garantir a efetividade das condições básicas para a formação de cidadãos críticos e atuantes a partir da Educação de Jovens e Adultos, no que tange ao direito assegurado pela legislação?

\section{REFERÊNCIAS}

BERTRAND, O. Avaliação e certificação de competências e qualificações profissionais. Olivier Bertrand. Brasília: UNESCO/ IIPE, 2005. p. 114. Disponível em: <http://unesdoc.unesco.org/images/0010/001085/108523por. pdf $>$ Acesso em: 28 de fevereiro de 2016. 
BRASIL. Ministério da Educação. Sistema Nacional de Certificação Profissional baseado em Competências. Brasília, DF: MEC, 2005.

BRASIL. Conselho Nacional de Educação. Parecer CNE/CEB n ${ }^{\circ}$ 11/2000. Institui as Diretrizes Curriculares Nacionais para a Educação de Jovens e Adultos . Brasília, DF: MEC, 2000.

BRASIL. Congresso Nacional. Lei n. 9394, de 20 de dezembro de 1996. Estabelece as Diretrizes e Bases da Educação Nacional. Diário Oficial da República Federativa do Brasil, Brasília, n.248, ano CXXXIV, 23 de dez. 1996.

BRASIL. Constituição Federal. Brasilia, DF: Senado Federal, 1988.

CIAVATTA, M.; FRIGOTTO, G.; RAMOS M. A Política de Educação Profissional no Governo Lula: um percurso histórico controvertido. Educ. Soc., Campinas, vol. 26, n. 92, p. 1087-1113, Especial - Out. 2005. Disponível em: http://www.scielo.br Acesso em: 14 de janeiro de 2016.

CURY, C. R. J. A qualidade da Educação Brasileira como Direito. Educ. Soc., Campinas, v.35, no 129, p. 1053-1066, out-dez, 2014. Disponível em: http:/ /www. scielo.br. Acesso em: 14 de janeiro de 2016.

DI PIERRO, M. C.; HADDAD, S. Transformações nas políticas de educação de jovens e adultos no Brasil no início do terceiro milênio: uma análise das agendas nacional e internacional. Caderno Cedes, Campinas, v. 35, n. 96, p. 197-217, maio-ago., 2015. Disponível em http://www.scielo.br. Acesso: 21 de janeiro de 2016.

FERREIRA, N. S. C. Repensando e Ressignificando a Gestão Democrática da Educação na "Cultura Globalizada”. Educ. Soc., Campinas, vol.25, n.89, p. 1227 1249, Set./Dez. 2004. Disponível em <http://www.cedes.unicamp.br> Acesso: 21 de janeiro de 2016.

FRIDRICH, M. et al. Trajetória da escolarização de jovens e adultos no Brasil: de plataformas de governo a propostas pedagógicas esvaziadas. Ensaio: aval. pol. públ. Educ., Rio de Janeiro, v. 18, n. 67, p. 389-410, abr./jun. 2010. Disponível em: <http://www.scielo.br. Acesso em: 26 de janeiro de 2016. 
FRIGOTTO, G. Os circuitos da história e o balanço da educação no Brasil na primeira década do século XXI. Revista Brasileira de Educação, v. 16, n 46, p. 235-274, jan./abr. 2011. Disponível em: http://www.scielo.br. Acesso em: 21 de janeiro de 2016.

SADER, E. Direitos e Esfera Pública. Serviço Social \& Sociedade, São Paulo, ano XXIV, no 77, p. 5-10, abril, 2004.

SAVIANI, D. O Plano de Desenvolvimento da Educação: análise do projeto do MEC. Educ. Soc., Campinas, v. 28, n. 100, p. 1231-1255, Oct. 2007. Disponível em: http://www.scielo.br/scielo. Acesso em 15 de janeiro de 2016.

VIEIRA, E. A Política e as Bases do Direito Educacional. Caderno Cedes, ano XXI, no 55, p. 9-29. Nov., 2001. Disponível em: www.scielo.br. Acesso em 14 de janeiro de 2016.

VALDIVINA ALVES FERREIRA é doutora em Educação pela PUC Goiás. Mestre em Educação pela UFMS. Docente do Programa de Pós-Graduação em Educação - Mestrado e Doutorado da Universidade Católica Dom Bosco (UCDB). E-mail: valdivina5784@hotmail.com

MARCILENE FERREIRA RODRIGUES é mestranda do Programa de PósGraduação em Educação - Mestrado e Doutorado da Universidade Católica Dom Bosco (UCDB). E-mail: llmarcilene@hotmail.com

Recebido em março de 2016 Aprovado em junho de 2016 